\title{
EVALUASI PENGEMBANGAN KAWASAN MINAPOLITAN KABUPATEN BULUKUMBA
}

\author{
Nurfaila Tasni ${ }^{\mathrm{a}}$, Irsyadi Siradjuddin ${ }^{\mathrm{a}}$, Fadhil Surur ${ }^{\mathrm{a}}$ \\ a Jurusan Teknik Perencanaan Wilayah \& kota, Fakultas Sains \& Teknologi, UIN Alauddin Makassar. \\ E-mail Correspondence: irsyadi.siradjuddin@uin-alauddin.ac.id
}

\begin{abstract}
Kabupaten Bulukumba merupakan satu kabupaten yang ditetapkan sebagai kawasan pengembangan minapolitan. Penerapan pengembangan minapolitan belum optimal disebabkan oleh ketersediaan infrastkruktur baik sarana dan prasarana maupun program pengembangan minapolitan belum memadai. Rujukan pengembangan minapolitan berdasarkan berdasarkan keputusan Menteri Kelautan dan Perikanan Republik Indonesia No.35/KEPMENKP/2013 tentang pedoman perencanaan pengembangan kawasan perikanan budidaya (minapolitan). Tujuan penelitian ini untuk mengetahui tingkat ketersediaan infrastruktur (sarana dan prasarana) dan pelaksanaan program di kawasan minapolitan Kabupaten Bulukumba. Hasil penelitian menunjukkan bahwa hasil evaluasi presentase infrastruktur kawasan minapolitan berdasarkan ketersediaan sarana yakni mencapai 44, $6 \%$ dengan kategori kurang. Sarana yang perlu ditambahkan ketersediaannya adalah pabrik es, pengolahan hasil perikanan, gudang pengolahan, lapangan penjemuran ikan, penyediaan benih, laboratorium, docking bengkel, dan coldroom. Evaluasi ketersediaan prasarana dengan presentase $66 \%$ berkategori sedang. Prasarana yang perlu ditambahkan ketersediannya adalah jaringan air bersih, jaringan telekomunikasi, dan dermaga. Tingkat pelaksanaan program pada pengembangan kawasan minopolitan di Kabupaten Bulukumba mencapai 80 \% dengan kategori baik. Mayoritas pelaksanaan program terlaksana dengan baik, namun masih perlu peningkatan dalam hal penyuluhan.
\end{abstract}

Keywords: Minapolitan, Evaluasi Kawasan, Bulukumba

\begin{abstract}
Bulukumba Regency is a district designated as a Minapolitan development area. The application of minapolitan development has not been optimal due to the inadequate availability of infrastructure, both facilities and infrastructure and the minapolitan development program. The reference for minapolitan development is based on the decision of the Minister of Maritime Affairs and Fisheries of the Republic of Indonesia No. 35/KEPMEN-KP/2013 concerning guidelines for planning the development of aquaculture areas (minapolitan). The purpose of this study was to determine the level of availability of infrastructure (facilities and infrastructure) and program implementation in the minapolitan area of Bulukumba Regency. The results showed that the results of the evaluation of the percentage of infrastructure in the Minapolitan area based on the availability of facilities reached $44.6 \%$ in the less category. Facilities that need to be added are ice factories, fishery product processing, processing warehouses, fish drying fields, provision of seeds, laboratories, docking workshops, and cold rooms. Evaluation of the availability of infrastructure with a percentage of $66 \%$ is in the medium category. The availability of infrastructure that needs to be added is a clean water network, telecommunications network, and docks. The level of program implementation on the development of the Minopolitan area in Bulukumba Regency reached $80 \%$ with a good category. The majority of program implementation has been carried out well, but there is still need for improvement in terms of outreach.
\end{abstract}

Keywords: Minapolitan, Area Evaluation, Bulukumba

How to cite (APA 6th Style):

Tasni, Nurfaila., Siradjuddin, Irsyadi., Surur, Fadhil. (2021). Evaluasi Pengembangan Kawasan Minapolitan Kabupaten Bulukumba, 2 (2), 1-6. doi: 10.26418/uniplan.v2i2.46721

\section{PENDAHULUAN}

Kabupaten Bulukumba merupakan salah satu kabupaten yang memiliki potensi wilayah dalam aspek maritim (kelautan dan perikanan), dimana Kabupaten Bulukumba memiliki garis pantai sepanjang 128 KM dan luas wilayah pengelolaan perairan 948.224 KM 2 dengan lokasi yang berada diantara 2 samudera yaitu Laut Flores \& Teluk Bone (Harmunanto et al., 2019). Pengembangan minapolitan berdasarkan berdasarkan keputusan Menteri Kelautan dan Perikanan Republik Indonesia No.35/KEPMEN-KP/2013 tentang pedoman perencanaan pengembangan kawasan perikanan budidaya (minapolitan) (TimDirektorat, 2010). 
Sejalan dengan pembangunan sektor perikanan dan kelautan maka diibutuhkan penangan khusus untuk mengoptimalkan pengelolahan hasil produksi perikanan di kabupaten Bulukumba dengan mengembangkan konsep minapolitan. Menurut Peraturan Daerah Tentang Rencana Tata Ruang Wilayah Kabupaten Bulukumba Tahun 2012-2032 (2011) Rencana Tata Ruang Wilayah (RTRW) untuk 2011-2031 menetapkan seluruh daerah pesisir sebagai Kawasan Pengembangan Minapolitan dengan pusat pengembangan terletak di Bontobahari dan Kajang kecamatan, sedangkan produksi sub-pusat berada di bawah kendali 8 kecamatan di Kabupaten Bulukumba, yaitu Kecamatan Bontotiro, Bulukumpa, Gantarang, Hero. Lange - lange, Kindang, Rilau Ale, Ujung Bulu, dan Ujung Loe.

Pengembangan kawasan berbasis minapolitan diharapkan dapat menjadi pendorong percepatan pengembangan kawasan yang berfungsi sebagai komoditas perikanan, tetapi juga diharapkan menjadi kawasan pengolahan, penyimpanan dan penjualan yang dapat membantu mendukung pengembangannya, hal tersebut dapat diwujudkan dengan cara mensinergikan berbagai potensi yang ada, hal ini dapat tercapai dengan adanya komitmen dari pemerintah daerah dan masyarakat dalam pengembangannya, namun dalam pengimplementasian kebijakan terkadang terkendala di lapangan, sehingga menimbulkan kesenjangan harapan dan kenyataan (Cahya \& Mareza, 2013). Tujuan penelitian ini untuk mengetahui tingkat ketersediaan infrastruktur (sarana dan prasarana) dan pelaksanaan program di kawasan minapolitan Kabupaten Bulukumba.

\section{DATA DAN METODE}

\subsection{Data}

Zona Pengembangan Minapolitan tersebar di 10 kecamatan di Kabupaten Bulukumba, meliputi perikanan tangkap dan budidaya. Perikanan tangkap dikembangkan di tujuh subkawasan pesisir yaitu subkawasan Gantarang, Ujung Bulu, Ujung Loe, Bonto Bahari, Bonto tiro, Herlang dan Kajang, sedangkan perikanan budidaya terdapat di seluruh subkawasan Kabupaten Bulukumba. Sebaran TPI dan PPI dapat dilihat pada Gambar 1. Menurut Muryadi (2017) model evaluasi yang digunakan dalam penelitian ini adalah evaluasi produk. Evaluasi produk merupakan evaluasi yang mengukur keberhasilan atau kegagalan pencapaian tujuan. Penilaian tersebut mencatat realisasi hasil dan keputusan untuk perbaikan dan realisasi.

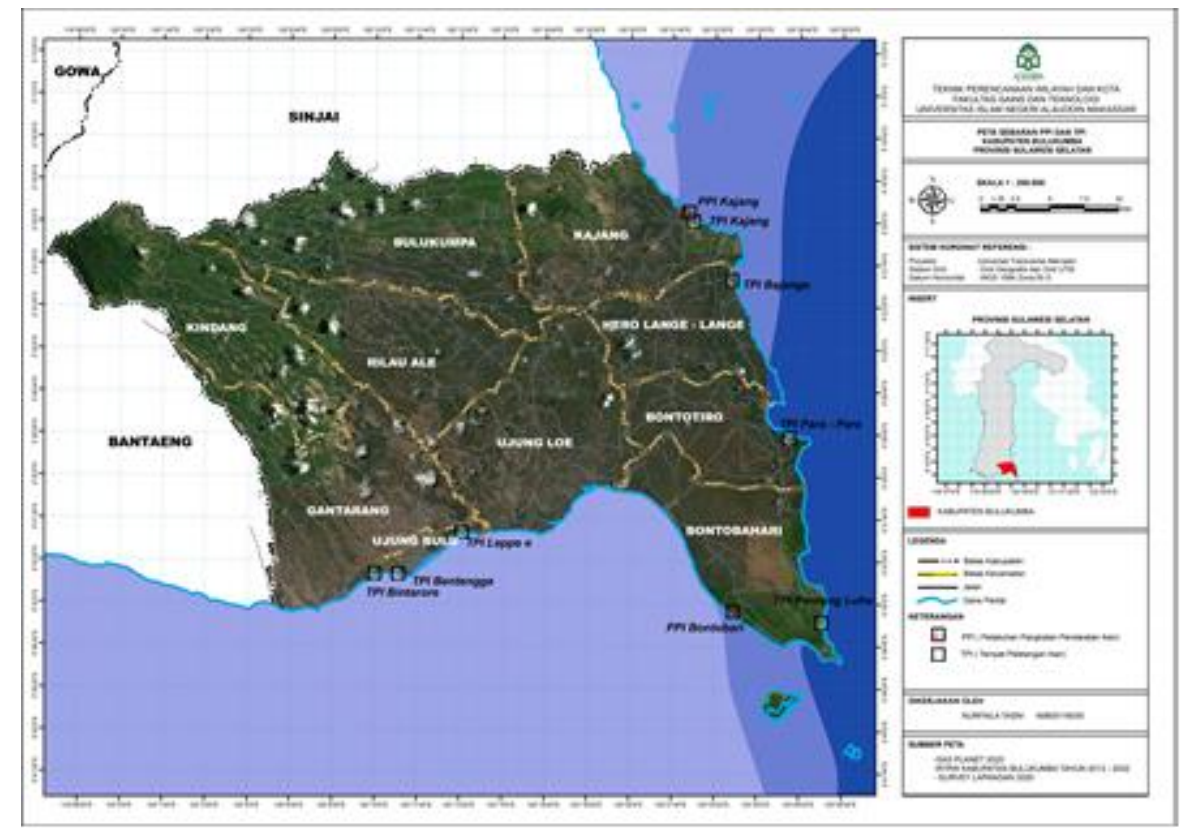

Gambar 1. Sebaran TPI dan PPI

Evaluasi tingkat ketersediaan infrastruktur yang terdiri dari sarana dan prasarana serta pelaksanaan program. Ketersediaan Infrastruktur didasarkan keputusan Direktur Jenderal Perikanan Budidaya nomor Kep. 10/DI-PB/2010 tentang pedoman perencanaan pengembangan kawasan perikanan budidaya (minapolitan). Evaluasi terhadap sarana berupa : 1. Lembaga masyarakat (Kelompok tani/Nelayan), 2. 
Tempat pelelangan ikan (TPI), 3.Pabrik es, 4. Lembaga keuangan (Bank dan koperasi), 5. Industri pengolahan ikan (kecil, rumah tangga), 6. SPBU/SPDN, 7. Gudang pengolahan/ pengepakan, 8. Lapangan penjemuran ikan, 9. Penyediaan benih, 10. Laboratorium, 11. Docking bengkel. Evaluasi terhadap prasarana berupa: 1. Jaringan jalan, 2. Jaringan air bersih, 3. Jaringan listrik, 4. Jaringan telekomunikasi, 5. Dermaga, dan 6. Jaringan irigasi. Evaluasi terhadap program pengembangan kawasan minapolitan yaitu : 1. pelatihan, 2. penyuluhan, 3. pembenihan dan 4. modal (home industri)

\subsection{Metode pengumpulan data}

Metode pengumpulan data adalah proses memperoleh data untuk keperluan penelitian. Beberapa bentuk pengumpulan data yang digunakan dalam penelitian ini, yaitu data primer yg dibutuhkan untuk penelitian ini yaitu kondisi fisik kawasan pengembangan Minapolitan di Kabupaten Bulukumba, ketersediaan sarana dan prasarana, serta kondisi sarana dan prasarana. Adapun data sekunder yg diperlukan dalam penelitian ini adalah data kependudukan yang meliputi jumlah penduduk, struktur mata pencaharian berdasarkan sektor perikanan, data produksi ikan dan pelaksanaan program berupa kelembagaan, pembinaan, pembenihan, penyediaan modal dan pengelolaan hasil perikanan seperti industri rumahan.

\subsection{Metode pengolahan data}

Metode analisis ini mengharuskan membandingkan tujuan yang ditetapkan dalam rencana dengan hasil program yang terlaksana. Hasil evaluasi dapat berupa nilai tes, persentase, data observasi, grafik data, pengukuran sosial, dan sebagainya dapat dicari sesuai tujuan yang lebih detail. Selain itu, analisis kualitatif mengapa hasilnya demikian. Keputusan untuk melaksanakan evaluasi pada setiap tahap evaluasi program dibagi menjadi tiga kategori yakni tinggi, sedang dan rendah.

1. Kategori tinggi dengan skor 5 (apabila $80 \%-100 \%$ terlaksana)

2. Kategori sedang dengan skor 3 (apabila $50 \%-79 \%$ telah tercapai tapi belum terwujud)

3. Kategori rendah dengan skor 1 (apabila $<50 \%$ belum terencana dan belum terwujud)

\section{HASIL DAN PEMBAHASAN}

Sumberdaya perikanan memiliki potensi untuk dijadikan sebagai motor penggerak Penggerak perekonomian nasional, namun hingga saat ini potensi tersebut belum dikelola secara optimal. Sejalan dengan pesatnya perubahan di berbagai bidang, kebijakan pembangunan perikanan perlu diubah atau disesuaikan (Asnawah et al., 2013). Adapun konsep wilayah adalah wilayah yang didasarkan pada keragaman material dan ekonomi, tetapi memiliki keterkaitan yang erat dan fungsional yang saling mendukung dalam mempercepat pertumbuhan ekonomi wilayah dan meningkatkan kesejahteraan masyarakat sebagai salah satu konsep wilayah yakni minapolitan (Arnawa et al., 2016). Minapolitan terdiri dari kata mina dan kata Polis (polis). Mina berarti ikan, dan Politan berarti kota, sehingga Minapolitan dapat diartikan sebagai kota nelayan atau kota nelayan atau daerah penangkapan ikan di daerah penangkapan ikan. Minapolitan adalah kota nelayan, berkembang dan berkembang karena sistem perikanan dan operasi perusahaan, yang dapat melayani, mendorong dan menarik kegiatan pembangunan ekonomi di daerah sekitarnya (Surbakti, 2019).

Terbentuknya konsep minapolitan diharapkan menjadi motor penggerak utama perekonomian, sehingga menciptakan kesejahteraan khususnya bagi masyarakat pesisir. Kesejahteraan adalah rasa damai yang dirasakan masyarakat karena terpenuhinya kebutuhan hidup internal dan eksternal masyarakat. Tunjangan kelahiran didasarkan pada standar umum mengenai kesehatan, pakaian, perumahan, dan makanan. kesejahteraan intrinsik melibatkan persepsi kecerdasan, emosi dan semangat, yaitu perasaan dilindungi dan realisasi hak-hak intelektual, emosional dan spiritual masyarakat (Wiratama, 2016). Agar terwujud kesejahteraan dan keberhasilan dalam pengembangan kawasan minapolitan maka diperlukan sarana dan prasarana. Secara umum, infrastruktur dan fasilitas Merupakan alat penunjang keberhasilan 
upaya pelayanan publik, karena tanpa kedua hal tersebut maka semua kegiatan yang dilakukan tidak akan mencapai hasil yang diharapkan seperti yang direncanakan (Lamia et al., 2017).

Tabel 1. Hasil rekapitulasi tingkat ketersediaan sarana kawasan minapolitan di Kabupaten Bulukumba (analisis 2020)

\begin{tabular}{|l|l|c|c|c|}
\hline No & \multicolumn{1}{|c|}{ Variabel } & Kategori & Nilai & $\begin{array}{c}\text { Tingkat } \\
\text { Ketersediaan (\%) }\end{array}$ \\
\hline 1 & $\begin{array}{l}\text { Kelembagaan masyarkat (Kelompok } \\
\text { nelayan/tani) }\end{array}$ & 5 & 90 \\
\hline 2 & Tempat pelelangan ikan (TPI) & 3 & 75 \\
\hline 3 & Pabrik es & 1 & 50 \\
\hline 4 & Lembaga keuangan (Koperasi \& Bank) & 5 & 100 \\
\hline 5 & Pengolahan hasil perikanan/industri rumahan & 1 & 50 \\
\hline 6 & SPBU/SPDN & 3 & 60 \\
\hline 7 & Gudang pengolahan/ pengepakan & 1 & 0 \\
\hline 8 & Lapangan penjemuran ikan & 1 & 0 \\
\hline 9 & Penyediaan benih & 1 & 20 \\
\hline 10 & Laboratorium & 1 & 0 \\
\hline 11 & Docking bengkel & 1 & 28 \\
\hline 12 & Lemari pendingin (Coldroom) & 1 & 50 \\
\hline 13 & Sarana sosial (pendidikan) & 5 & 100 \\
\hline & & 29 & 623 \\
\hline
\end{tabular}

Berdasarkan Tabel 1 hasil evaluasi tingkat pelaksanaan kawasan minapolitan berdasarkan ketersediaan sarana yakni mencapai 44, $6 \%$ dengan kategori kurang, dimana masih perlu penambahan fasilitas dan perbaikan fasilitas yang ada guna mencapai pelaksanaan program yang baik. Ketersediaan sarana minapolitan yang perlu disediakan yaitu gudang pengolahan dan pengepakann, lapangan penjemuran ikan, dan laboratorium. Menurut Departemen Pekerjaan Umum (2012) kebutuhan fisik pengembangan sarana pada kawasan minapolitan sulawesi tenggara adalah pembangunan dermaga kayu.

Hasil rekapitulasi tingkat ketersediaan prasarana di kawasan Minapolitan Kabupaten Bulukumba dapat dilihat pada Tabel 2. Hasil evaluasi tingkat pelaksanaan kawasan minapolitan berdasarkan ketersediaan prasarana yakni mencapai $66 \%$ dengan kategori sedang, dimana pembangunan prasarana di Kabupaten Bulukumba berjalan dengan baik, namun masih perlu beberapa perbaikan demi tercapainya kelancaran program pengembangan minapolitan di Kabupaten Bulukumba.

Tabel 2. Hasil rekapitulasi tingkat ketersediaan prasarana kawasan minapolitan di Kabupaten Bulukumba (analisis 2021)

\begin{tabular}{|l|l|l|l|c|}
\hline No. & \multicolumn{1}{|c|}{ Variabel } & Kategori & Nilai & $\begin{array}{c}\text { Persentase tingkat } \\
\text { ketersediaan }\end{array}$ \\
\hline 1 & Jaringan jalan & 5 & 95 & \multirow{2}{*}{} \\
\cline { 1 - 3 } 2 & Jaringan Air Bersih & 1 & 33 & \multirow{2}{*}{$66 \%$} \\
\hline 3 & Jaringan Listrik & 5 & 100 & \multirow{2}{*}{} \\
\hline 4 & Jaringan Telekomunikasi & 1 & 42 & \\
\hline 5 & Dermaga & 3 & 57 & \\
\cline { 1 - 3 } 6 & Jaringan Irigasi & 5 & 100 & \\
\cline { 1 - 2 } Jumlah & 20 & 427 & \\
\hline
\end{tabular}

Perbaikan prasarana yang dibutuhkan sebagai bagian dari pengembangan kawasan minapolitan di Bulukumba yaitu jaringan air bersih, jaringan telekomunikasi dan dermaga. Menurut (Budiarti et al., 2021) 
menurut data yang diperoleh Berdasarkan hasil evaluasi PDAM hampir menjangkau seluruh lokasi pengembangan minapolitan. Kebanyakan Masyrakat mengandalkan sumur bor sebagai sumber air bersih dimana Sarana air bersih di kawasan TPI/PPI, untuk persampahan kebanyakan masyarakat masih mengandalkan sistem konvensional, dan sanitasi yang belum terpenuhi dengan baik sehingga bau busuk sangat menyengat khususnya di kawasan pelelangan ikan.

Tabel 3. Rekapitulasi Pelaksanaan Program

Kawasan Minapolitan di Kabupaten Bulukumba (analisis 2021)

\begin{tabular}{|c|c|c|c|c|}
\hline No & Varabel & Kategori & Nilai & Tingkat pelaksanaan \\
\hline 1 & Pelatihan & 5 & 100 & \\
\hline 2 & Penyuluhan & 1 & 42 & \multirow{2}{*}{$80 \%$} \\
\hline 3 & pembenihan & 5 & 90 & \multirow{2}{*}{80} \\
\hline 4 & Modal (Home industry) & 5 & 100 & \\
\cline { 1 - 3 } & Jumlah & 16 & 332 & \\
\hline
\end{tabular}

Rekapitulasi tingkat pelaksanaan program di kawasan pengembangan Minapolitan Kabupaten Bulukumba yakni pada Tabel 3. Tingkat pelaksanaan program pada pengembangan kawasan minopolitan di Kabupaten Bulukumba ini mencapai 80 \% Dengan kategori baik secara keseluruhan program telah terlaksana sebagai upaya pemerintah dalam mengembangkan kawasan minapolitan, namun perlunya optimalisisasi sehingga impact program menyentuh seluruh lapisan masyarkat, utamnya masyarakat yang membutuhkan uluran tangan pemerintah seperti halnya pemberian modal (home industry), sehingga masyarakat lebih mudah menjalanka usahanya. Menurut Rudiono et al., (2014) tujuan keseluruhan dari program Minapolitan adalah untuk meningkatkan kesejahteraan dan standar Kehidupan masyarakat, khususnya nelayan dan pembudidaya ikan, melalui pengembangan wilayah Perairan/pesisir yang kegiatan utamanya adalah sektor kelautan dan perikanan.

Program pengembangan kawasan minapolitan bertujuan: (a) Meningkatkan produksi, produktivitas, dan kualitas hasil kelautan dan perikanan; (b) Meningkatkan pendapatan nelayan, pembudidaya ikan, dan pengolahan ikan secara adil dan merata; mengembangkan kawasan minapolitan menjadi pusat pertumbuhan ekonomi kawasan (Muchlisin et al., 2012). Menurut Siradjuddin (2011) Secara umum motivasi petani untuk mengikuti program ini adalah untuk meningkatkan produksi \& mendapatkan bantuan dalam bentuk modal atau sarana produksi, meskipun berupa pinjaman. Menurut (Santoso et al., 2019) dengan adanya pengembangan minapolitan menjadikan wilayah berkembang pesat pembangunannya melebihi wilayah sekitarnya seiring dengan peningkatan pendapatan masyarakat.

\section{KESIMPULAN}

Hasil evaluasi presentase infrastruktur kawasan minapolitan berdasarkan ketersediaan sarana yakni mencapai 44, $6 \%$ dengan kategori kurang. Sarana yang perlu ditambahkan ketersediaannya adalah pabrik es, pengolahan hasil perikanan, gudang pengolahan, lapangan penjemuran ikan, penyediaan benih, laboratorium, docking bengkel, dan coldroom. Evaluasi ketersediaan prasarana dengan presentase $66 \%$ berkategori sedang. Prasarana yang perlu ditambahkan ketersediannya adalah jaringan air bersih, jaringan telekomunikasi, dan dermaga. Tingkat pelaksanaan program pada pengembangan kawasan minopolitan di Kabupaten Bulukumba mencapai 80 \% dengan kategori baik. Mayoritas pelaksanaan program terlaksana dengan baik, namun masih perlu peningkatan dalam hal penyuluhan.

\section{DAFTAR PUSTAKA}

Arnawa, I. K., Martiningsih, G. A. G. E., \& Sukerta, I. M. (2016). Konsep Rencana Pengembangan Kawasan 
Minapolitan Kabupaten Gianyar. Prosiding Semnas Hasil Penelitian, O(0), 508-518. http://jurnal.unmas.ac.id/index.php/pros/article/view/337/299

Asnawah, Y. K., Efani, A., \& Tjahjono, A. (2013). Evaluasi Terhadap Implementasi Program Pengembangan Kawasan Minapolitan Perikanan Tangkap di Pelabuhan Perikanan Nusantara (PPN) Brondong Kabupaten Lamongan Jawa Timur. Jurnal ECSOFiM, 1(1), 97-108.

Budiarti, W., Siradjuddin, I., \& AP., A. I. (2021). Arahan Pengembangan Desa Wisata di Desa Pincara Kabupaten Luwu Utara. Jurnal IImiah Membangun Desa Dan Pertanian (JIMDP), 6(1), 14-24. https://doi.org/http://dx.doi.org/10.37149/JIMDP.v6i1.15515

Cahya, D. L., \& Mareza, M. D. (2013). Konsep Pengembangan Kawasan Minapolitan Ketapang Kabupaten Lampung Selatan. Planesa, 4(2), 46-52.

Departemen Pekerjaan Umum. (2012). Agropolitan \& Minapolitan Konsep Kawasan Menuju Keharmonian. Kementerian Pekerjaan Umum.

Harmunanto, D. H., Akil, A., \& Ihsan, I. (2019). POTENSI PERIKANAN DALAM PENINGKATAN PEREKONOMIAN Studi Kasus di Kabupaten Bulukumba, Sulawesi Selatan. Seminar Nasional Geomatika, 3, 325. https://doi.org/10.24895/sng.2018.3-0.972

Peraturan Daerah Tentang Rencana Tata Ruang Wilayah Kabupaten Bulukumba tahun 2012-2032, 1 (2011). https://sippa.ciptakarya.pu.go.id/

Lamia, L. B., Rengkung, M. M., \& Takumansang, E. D. (2017). Ketersediaan Prasarana Sarana Mendukung Kawasan Minapolitan di Kabupaten Minahasa Selatan. SPASIAL : PERENCANAAN WILAYAH DAN KOTA, $4(2), 19-27$.

Muchlisin, Z. a, Nazir, M., Musman, M., Perairan, J. B., \& Kelautan, K. (2012). Pemetaan potensi daerah untuk pengembangan kawasan minapolitan di beberapa lokasi dalam Provinsi Aceh : suatu kajian awal Mapping of the potencial locations for developing minapolitan region in Aceh Province : a preliminary study. 1(April), 68-77.

Muryadi, A. D. (2017). Model Evaluasi Program Dalam Penelitian Evaluasi. Jurnal IImiah PENJAS, 3(1), 1-14.

Rudiono, Harsasto, P., \& Ahmad Taufiq. (2014). Evaluasi Pelaksanaan Program Minapolitan tahun 20092011 di Kabupaten Banyumas. Jurnal Ilmu Pemerintahan, 3(1), 1-9.

Santoso, E. B., Moenek, R., \& Nurpahdi, M. (2019). Evaluasi Kebijakan Pengembangan Kawasan Minapolitan di Kabupaten Bogor. Jurnal IImu Pemerintahan Widya Praja, 45(1), 17-32. https://doi.org/10.33701/jipwp.v45i1.351

Siradjuddin, I. (2011). Dampak Pengembangan Kapas Transgenik Terhadap Perekonomian Wilayah di Kabupaten Takalar, Bantaeng, dan Bulukumba. Jurnal Agroteknologi, 2(1), 35-49.

Surbakti, A. P. L. (2019). Analisis Tingkat Pelayanan Infrastrruktur Pendudkung Kawasan Minapolitan Petasia Di Kabupaten Morowali Utara. Spasial, 6(1), 1-13.

TimDirektorat, P. dan S. B. (2010). Pedoman Perencanaan Pengembangan Kawasan Perikanan Budidaya (Minapolitan). Direktorat Jenderal Prasarana dan Sarana Budidaya, Direktorat Jenderal Perikanan Budidaya, Kementerian Kelautan dan Perikanan.

Wiratama, A. (2016). Dampak Implementasi Program Minapolitan Terhadap Kesejahteraan Masyarakat Di Kecamatan Muncar Kabupaten Banyuwangi. Kebijakan Dan Manajemen Publik, 4(1), 14. 